\title{
Consciousness and Intentionality in Franz Brentano
}

\author{
Mauro Antonelli ${ }^{1}$
}

Received: 8 February 2021 / Accepted: 1 July 2021 / Published online: 20 August 2021

(c) The Author(s) 2021

\begin{abstract}
The paper argues against the growing tendency to interpret Brentano's conception of inner consciousness in self-representational terms. This trend has received support from the tendency to see Brentano as a forerunner of contemporary sameorder theories of consciousness and from the view that Brentano models intransitive consciousness on transitive consciousness, such that a mental state is conscious insofar as it is aware of itself as an object. However, this reading fails to take into account the Brentanian concept of object, which is ultimately derived from ancient and medieval philosophy, as well as the secondary, elusive character that Brentano attributes to inner perception. According to Brentano, we have an aspectual but transparent consciousness of transcendent objects, whereas our awareness of our own mental acts is always complete but incidental, and ultimately opaque. Reversing the relationship between intentionality and consciousness faces difficulties at the textual interpretative level, but also raises theoretical problems, for it risks treating Brentano's theory of mind as a form of subjectivism and idealism.
\end{abstract}

Keywords Franz Brentano $\cdot$ Consciousness $\cdot$ Intentionality $\cdot$ Selfrepresentationalism · Intentional object

\section{Introduction}

For a long time, Brentano has been almost universally viewed as the philosopher of intentionality. In recent years, however, the focus of the philosophical debate has increasingly been placed on his conception of consciousness, to the point that

Mauro Antonelli

mauro.antonelli@unimib.it

1 Department of Psychology, University of Milano-Bicocca, Piazza dell'Ateneo Nuovo, 1, 20126 Milano, Italy 
some interpreters have read his original intentionality thesis of mental phenomena in terms of a theory of "phenomenal intentionality".

The current debate about the relationship between intentionality and consciousness ${ }^{1}$ can be viewed as largely the consequence of the focus placed in analytic philosophy on the so-called hard problem of consciousness since the publication in 1996 of David Chalmers' The Conscious Mind (1996). What form does a thought need to take in order to be self-conscious? What kind of representation makes our thoughts aware of themselves? In this respect, two major groups of theories have come into conflict, namely, higher-order theories of consciousness and same-order, or self-representational, theories of consciousness.

Higher-order theories, as proposed by scholars such as David Rosenthal (1986), Peter Carruthers (1996), and Rocco Gennaro (1996), are based on the thesis of reflection: a mental state is conscious in virtue of a further, higher-order mental state, which refers to it and thus makes it conscious. Such a state ${ }^{2}$ may in turn be either conscious or unconscious. If the higher-order state is unconscious, however, the difficulty arises of how to account for the direct phenomenological evidence of consciousness. If consciousness is an immediate, phenomenologically indisputable datum, it seems problematic to attribute this characteristic to an unconscious event of a subpersonal nature. Furthermore, like first-order representation, a higher-order representation can also misrepresent not only the properties of its target but also its very existence. Since a representation is distinct from what it represents, the possibility of error cannot be ruled out; the subject can live with the illusion of being in a conscious state which is not what it seems to be or does not even exist at all. On the other hand, if the higher-order state is conscious, then the problem of infinite regress arises: the higher-order state is in turn conscious by virtue of an even higher-order state, and so on ad infinitum.

Against the thesis of reflection and its problematic aspects, some scholars have advanced the self-reflectivity model (encompassing the same-order theories), according to which a mental state is conscious insofar as it refers not only to something else but also to itself. For theorists such as Kenneth Williford (2006), and Uriah Kriegel $(2006,2009)$, it is not necessary that a higher-order representation be present for self-consciousness to emerge; the primary state of consciousness and the reflection on it - or, as these theorists put it, its representation - should not be attributed to two (numerically and temporally) ${ }^{3}$ distinct mental states, but to one and the same state, which in addition to representing something also co-represents itself. "Thus, whatever else a conscious state represents, it always also represents itself, and it is in virtue of representing itself that it is a conscious state" (Kriegel, 2009, pp. 13-14). Thus, according to self-representationalism, every mental state $M_{1}$ is (phenomenally) conscious not in virtue of being suitably represented by a numerically distinct mental state $\mathrm{M}_{2}$; rather, $\mathrm{M}_{1}$ and $\mathrm{M}_{2}$ are the same token mental state,

\footnotetext{
1 For an overview, see Siewert, 2020.

2 According to some scholars, this state exerts a perceptual monitoring action (Armstrong, 1968; Lycan, 1987, 1997), while according to others it has the character of thought (Rosenthal, 1993).

3 Rosenthal (1986, p. 335), for instance, speaks of "roughly contemporaneous" states or thoughts.
} 
such that $\mathrm{M}_{1}$ represents its own occurrence. In other words, the self-representational theory of consciousness holds that a mental state is conscious if and only if it represents itself. On this view, conscious states both represent and are represented, and are conscious in virtue of both representing and being represented. The awareness of a conscious state is thus intrinsic to that same state. This form of self-awareness is "ubiquitous", that is, it is present wherever conscious events occur (see Kapitan, 1999, 2006; cf. Williford, 2006, p. 111).

In the context of the development of an alternative to higher-order theories of consciousness, some scholars such as Dan Zahavi (1998), Amie L. Thomasson (2000), Keith Hossack (2002), and Uriah Kriegel (2003a) have resorted to the Brentanian notion of secondary consciousness. According to Brentano, every mental state has a primary object (its intentional object), which in a sensory experience is a physical phenomenon like a sound or a colour, and at the same time it is conscious insofar as it presents itself as a secondary object, that is, a purely mental phenomenon (Brentano, 1924-1928, I, p. 180, Eng. p. 98). However, Brentano's solution and his thesis of the secondary object is considered inadequate by phenomenologists such as Zahavi (1998, 1999, 2004, 2006), following the criticism already made against Brentano by some members of the Heidelberg School, such as Dieter Henrich (1970), Ulrich Pothast (1971), and Konrad Cramer (1974). They criticized Brentano for modelling intransitive consciousness on transitive consciousness, that is, for conceiving of a mental state as conscious insofar as one is aware of it as an object. In this respect, Zahavi considers the Husserlian model superior, in the sense that the experience is given to the subject in a pre-reflective manner as experienced (erlebt), and not in objectivized way.

I agree with Zahavi, who argues for a non-representational account of consciousness in the phenomenological tradition. However, unlike Zahavi and in contrast to Kriegel's reading of Brentano's account of inner consciousness, I argue that, as it is for the phenomenological tradition, so too for Brentano being conscious of our own mental acts means that we are living through them. I believe this view can be interpreted as an unstructured self-awareness; unlike Zahavi, however, I maintain that Brentano characterizes this kind of consciousness not as an introspective capacity of inner life, but rather as an inner perception. I agree with Kriegel, who conceives of reflectivity of consciousness as an intrinsic feature of experience, but I disagree with him about its representational nature and structure.

Recently, the representationalist reading of Brentano has begun to be questioned. Montague (2019), for instance, has argued that Brentano's notion of presentation (Vorstellung) has little in common with contemporary representationalist theories. Similarly, both Dewalque (2020) and Seron (2020) have contended that Brentano's inner consciousness is not a type of self- or inward-directed intentionality and that Brentano therefore is not self-representationalist. While remaining attentive to historical specificity, this paper pursues the same conceptual line, intervening in contemporary discussions of alternative conceptions of (inner) consciousness by leveraging Brentano's Aristotelian background.

The paper is structured as follows. Section 1 problematizes the prevailing tendency to interpret Brentano's theories of intentionality and consciousness in representational terms and emphasizes that the idea of a self-representational inner 
consciousness is closer to German, particularly Fichtian, idealism than to Brentano's own anti-idealistic view. I contend that Brentano in fact deliberately recovered and advanced the Aristotelian realist tradition - not only in his early exegetical works on Aristotle but throughout his career, from his early Psychology (1874) through his later reism. I argue that we therefore should employ the term "self-awareness" when referring to Brentano's thought rather than the stronger notion of self-consciousness, which is instead appropriate for idealist and Fichtian circles. Section 2 takes up Brentano's concepts of consciousness and unconsciousness and shows that intentionality and (self-)awareness, though co-extensive, enjoy a specific relationship in which the latter is founded on the former and not vice versa, as self-representationalists claim. Section 3 locates one of the main causes of representational misreadings of Brentano in a widespread misunderstanding of his concept of object, which is derived from the legacy of Aristotelian scholarship. Section 4 highlights the influence of this Aristotelian heritage on Brentano's model of inner consciousness by foregrounding the distinction he makes between a primary and a secondary object in every mental act: the fact that a conscious state has itself as a secondary object in Brentano's Aristotelian terms does not imply it is a state we are conscious of as an object in the ordinary sense of this word (i.e., transitively). This difference between primary and secondary objects is the origin of the veridical and self-evident character of inner awareness as well as of its accessory and pre-reflective character. Finally, Sections 5 and 6 elaborate a phenomenological interpretation of Brentano's inner perception as a form of unthematic and pre-reflective awareness.

\section{Brentano's Alleged Representationalism}

It is important to begin from the almost undisputed assumption dominant in today's philosophy of mind and cognitive science that the terms "intentionality" and "representation" can be used synonymously and interchangeably. Intentionality is usually understood as the representational character of mind or consciousness - its being "of" or "about" or standing for things, properties, and states of affairs. To say that a mental state has intentionality is to say that it is a mental representation or that it has a content. A mental state or experience is intentional insofar as it is a representation of something other than itself.

Indeed, the use of the concepts of representation and self-representation to capture precisely the Brentanian concepts of intentionality and inner consciousness poses serious problems. Such a use seems at first sight to be justified by the Brentanian thesis that "the term 'mental phenomena' applies to presentations (Vorstellungen) as well as to all the phenomena which are based upon presentations. [...] This act of presentation forms the foundation not merely of the act of judging, but also of desiring and of every other mental act. Nothing can be judged, desired, hoped or feared, unless one has a presentation of that thing" (Brentano, 1924-1928, I, p. 112, Eng. p. 61). However, to translate the Brentanian term Vorstellung as "representation", as this term is currently understood in the philosophy of mind, is entirely misleading. Firstly because Brentano repeatedly insists that by presentation (Vorstellung) he does not mean a mental content 
but a mental act: "By presentation I do not mean that which is presented, but rather the act of presentation" (Brentano, 1924-1928, I, p. 111, Eng. p. 60). Moreover, because etymologically "representation" refers to a vicarial relationship, whereby something keeps the place of (or stands in for) something else, without being this other thing: for example, a flag represents a nation, but it is not this nation, a fever represents an inflammatory state of the organism, but it is not this state, and so on. This entails not only that there is an insurmountable gap between representation and what it represents, in the sense that representation and represented are (and must be) entirely distinct, but also that the relationship between representation and what it represents is indirect. The meaning of the Brentanian concept of Vorstellung is quite different: it does not refer to an inner representation of external things, but merely presents something actively to the mind or consciousness, directly and without any mediation: "As we use the verb 'to present' (vorstellen), 'to be presented' means the same as 'to appear' (erscheinen)" (Brentano, 1924-1928, I, p. 114, Eng. p. 62) — where "to appear" is used not in the epistemological sense of what seems to be as opposed to what is in reality, but in the purely phenomenological one of manifesting itself, of being placed (stellen) before (vor) the mind. Sensing (or presenting) cold does not mean having the idea of cold in the mind; it simply means experiencing cold.

It is even more problematic to explain Brentano's inner consciousness in (self-) representational terms. Same-level theories argue that a conscious act is conscious in virtue of some representational relation it bears to itself. This means that an act is conscious in virtue of taking itself as an object. The main concern with same-level theories is that they assume that our being conscious of a mental state requires an intentional state. Hence, consciousness can be explained only in terms of a structured representational content. But did Brentano intend something like this when he introduced the concept of secondary awareness? I think we must resist this representational account of consciousness, simply because in Brentano's psychology conscious activity is not a representation of anything.

With his "self-representationalism", Uriah Kriegel is today the most ardent supporter of the Brentanian origin of the self-representational model of consciousness (see Kriegel, 2003b, 2013, 2018a). Kriegel analyses conscious phenomenal states - that is, phenomenal consciousness — as involving a qualitative component ("qualitative character") and a "for-me component", which he also calls "subjective consciousness". While the latter captures the existence condition of conscious states, the first captures their identity status, that is, what makes a conscious state the phenomenally conscious state that it is (Kriegel, 2009, pp. 1-2). To give a concrete example: "In your auditory experience of the bagpipe you are aware primarily, or explicitly, of the bagpipe sound; but you are also implicitly aware that this auditory experience of the bagpipe is your experience" (Kriegel, 2003a, p. 104). The fundamental structure of consciousness therefore involves (1) the awareness of an object ("bagpipe sound"), (2) a self ("your experience"), and (3) the self-representation of this awareness ("auditory experience of the bagpipe"). Explicitly referring to Brentano, Kriegel states: “To my mind, this is Brentano's most striking thesis: that the very possibility of representing an apple, say, depends on the possibility of self-representing to represent an apple" (Kriegel, 2013, p. 24). 
However, this idea of consciousness is much more similar to the dominant conception in German idealism than to that of Brentano. Fichte in particular considered self-consciousness to be an Ego-consciousness that worms its way into the consciousness of an object, coming even to identify itself with the latter: "By your being aware of any object, for example, the wall in front of you, you are [...] properly aware of your thinking of this wall, and only to the extent you are aware of this thinking, is a consciousness of the wall possible" (Fichte, 1797, p. 526). At the basis of the Fichtian conception lies the idea that if consciousness is representation (Vorstellung) - that is, consciousness or representation of something - I can be aware of this something only if I know that I represent this something and that $I$ am the one who represents it. This is why self-consciousness (Selbstbewusstsein) is needed; otherwise, I could not distinguish between objects and the representations of objects (see Frank, 2015, pp. 44-47; see also Boccaccini, 2015).

However, all this is entirely foreign to Brentano. This is not so much because his conception of consciousness, at least in Psychology from an Empirical Standpoint (1874), is non-egological (see Textor, 2013); this point, however important, here appears to be entirely secondary. Rather, it is because at the basis of Kriegel's thesis lies the idea that the conscious representation of a primary object (Bewusstsein) presupposes and is necessarily founded on the conscious representation of a secondary object, what Kriegel calls "self-representation" (Selbstbewusstsein). In fact, as I read Brentano, this seems to me a transcendental-idealistic account of consciousness as a reflective structure founded on a representational activity of the mind. However, this view is both alien and unacceptable to Brentano, who identified Aristotle as the teacher who enabled him to overcome the influence of the period's German idealism. Like Aristotle, Brentano maintains an opposing point of view, namely, that transitive consciousness, i.e., intentionality, founds and makes possible intransitive self-awareness.

The following remarks aim at reconstructing, in a strictly contextualist way, ${ }^{4}$ the relationship between Brentano's concepts of intentionality and consciousness. They are to be understood as objections to the self-representational reading of Brentano, and not to self-representationalism as such. It goes without saying that the self-representationalism that can (possibly) be attributed to Brentano, and which is criticized here, must be compatible with two basic theses that characterize his psychology and philosophy of the mind: the co-extension of mental and conscious states, on the one hand, and the dualism of physical and mental phenomena on the other.

\section{Brentano: Consciousness and Unconsciousness}

Just as it did in the nineteenth century, the term "consciousness" has multiple meanings today, given the many contexts in which it is used in both scientific and ordinary language (Brentano, 1924-1928, I, pp. 141-142, Eng. p. 78). In demarcating

\footnotetext{
4 The reference is to the distinction between "appropriationist" and "contextualist" approaches in the history of philosophy, formulated by Laerke, Smith \& Schlisser, 2013, pp. 1-6.
} 
the meaning of the term, Brentano adopts a very specific position: consciousness is intentional in terms of its directedness (Richtung) towards something outside the mind; intentionality is thus the root of consciousness, and conversely the root of intentionality is the conscious experience of the subject. Consciousness and intentionality are not two separate features of mental acts; rather, consciousness is an intrinsic property of mental phenomena, that is, intentional acts. As Brentano puts it, "the term 'consciousness', since it refers to an object which consciousness is conscious of, seems to be appropriate to characterize mental phenomena precisely in terms of its distinguishing characteristic, i.e., the property of the intentional inexistence of an object, for which we lack a word in common usage" (Brentano, 1924-1928, I, pp. 142-143, Eng. pp. 78-79).

It is precisely the intentional nature of conscious experience that serves as the criterion for distinguishing the mental from the physical and physiological, and it is to the latter that the unconscious should also be ultimately assigned. In other words, those "habitual dispositions resulting from previous [mental] acts" which, being neither conscious nor intentional, are not even mental, but rooted in the bodily dimension (Brentano, 1924-1928, I, pp. 124-125, Eng. p. 45). On the other hand, Brentano admits that it is appropriate to ask whether it is possible to speak of an "unconscious consciousness". In attempting to determine the precise meaning of the term "unconscious", Brentano writes:

We use the term "unconscious" in two ways. First, in an active sense, speaking of a person who is not conscious of a thing; secondly, in a passive sense, speaking of a thing of which we are not conscious. In the first sense, the expression "unconscious consciousness" would be a contradiction, but not in the second. It is in the latter sense that the term "unconscious" is used here. (Brentano, 1924-1928, I, p. 143, n., Eng. p. 79, n. ${ }^{\ddagger}$ )

"Unconscious" in the first sense therefore means non-intentional. "Unconscious consciousness" would mean in this case that one is aware of something of which one is not conscious, which is obviously contradictory. However, it is legitimate to use the term "unconscious" in the second sense and to argue that someone sees something without being aware of seeing it, that is, that she sees it unconsciously.

However, it is crucial to emphasize that the possibility of an unconscious mental act understood in this latter sense is not, according to Brentano, contradictory in principle. While it would be contradictory to think of a mental act that is not intentional, it is legitimate to think of a mental phenomenon that is not accompanied by inner consciousness. As Brentano puts it: "An unconscious consciousness is no more a contradiction in terms than an unseen case of seeing" (Brentano, 1924-1928, I, p. 143, Eng. p. 79). In other words, it is not essential to consciousness that it includes inner perception of itself. For a mental act, being accompanied by inner perception is not a logical necessity, but only a necessary condition which follows from intentionality with nomological necessity.

In the second book of his Psychology from an Empirical Standpoint, in his search for distinctive marks of mental phenomena that could distinguish them from physical ones, Brentano brings into play both intentionality and accessibility to inner perception. But while he states of accessibility to inner perception that through it 
"the mental phenomena are sufficiently (genügend) characterized" (Brentano, 1924-1928, I, p. 129, Eng. p. 70), he considers intentionality "the feature which among all undoubtedly best (unter allen am meisten) characterizes mental phenomena" (Brentano, 1924-1928, I, p. 137, Eng. p. 75, slightly modified). Putting all this in terms of the Aristotelian-scholastic thought to which Brentano is committed, one might say that while intentionality — or rather intentional in-existence - is an essential property of the mental act, and so must be part of its definition, accessibility to inner perception constitutes a "proper accident" or " $\delta 10 \nu$ (proprium) of the mental act, as "capable of learning grammar" is a proprium of man (Aristotle, Top. I.5, 102a20-25); as such, it is coextensive with intentionality (i.e., intentional in-existence) but is not part of its definition. ${ }^{5}$ Not by chance, most of the analyses of "inner consciousness" that Brentano develops in the first book of Psychology from an Empirical Standpoint are aimed precisely at highlighting a series of findings that rule out the existence of unconscious mental acts (Brentano, 1924-1928, I, pp. 147-194, Eng. pp. 81-106).

Thus, although Brentano argues that all conscious states are innerly aware, he maintains that they are conscious in virtue not of their being innerly perceived or represented (or their self-representing, in the jargon of self-representationalism), but of their being directed towards something. Therefore, even upholding the assumptions of a self-representationalist reading of inner consciousness, Brentano cannot be considered a self-representationalist, since in self-representationalism conscious states are conscious in virtue of being self-representational - or rather, there is no intentionality without self-directed representation: "no representation without selfrepresentation" (Kriegel, 2013). Let us therefore take a closer look at the relationship between consciousness as intentionality and consciousness as inner awareness.

\section{Intentionality and Consciousness}

If consciousness is first and foremost intentional - that is, if it is directed towards the world and to what transcends it - it is also to some extent directed towards itself, that is, to what happens within consciousness itself: its experiences, the processes taking place in it, and its own contents. Brentano emphasizes that this form of consciousness is present in every mental phenomenon, enabling us to grasp in each experience not only its reference to an objectual otherness, but also its being conscious of itself. What characterizes the whole set of mental phenomena is "the

\footnotetext{
5 A proprium is a necessary but non-essential property of a species, deeper than an accident but not yet essential. As such it does not appear in the real definition of a species, though it belongs to all its members and nothing else. In this sense, a proprium is an accident which follows or flows of necessity from the essence of a thing, but is not explanatorily basic and is not actually required for the continued existence of a thing. As such, it is nomologically necessary, but contingent in the "metaphysical" sense. Consider the classic example of the ability to laugh: though it belongs to all men, it is not an essential property of man, whose Aristotelian definition as "rational animal" does not require laughter. This property flows from the complete possession of biological (and therefore animal) organs capable of producing sounds on the one hand, and of the (rational) ability to grasp a joke on the other.
} 
fact that they are only perceived in inner consciousness, while in the case of physical phenomena only external perception is possible" (Brentano, 1924-1928, I, p. 128, Eng. p. 70). This does not yet make the essential point, however, unless one adds that "inner perception possesses another distinguishing characteristic: its immediate, infallible self-evidence. Of all the types of knowledge of the objects of experience, inner perception alone possesses this characteristic" (ibid.).

Thus, inner perception as compared to outer perception has the advantage of grasping the real being of the perceived: only in inner perception are being and appearing one and the same. This is because "inner perception is not merely the only kind of perception which is immediately evident; it is really the only perception in the strict sense of the word" (ibid.). While in outer perception nothing assures us that the physical phenomenon actually exists as it appears, in inner perception one is genuinely in the presence of that "grabbing of the truth" which is hinted at in the etymology of the term Wahrnehmung (Brentano, 1924-1928, I, p. 129, Eng. p. 70). Inner perception is in fact a judgement, a certain and evident knowledge of the mental act.

However, the two forms of consciousness have to be regarded as inseparably connected. The perception of an object and the awareness of perceiving it cannot be understood as distinct and mutually independent mental acts that are only accidentally related to each other, since the very possibility of speaking, in a descriptive context, of a mental act requires that this act be something of which one is conscious. But what is the nature of this connection?

In order to grasp Brentano's theory of inner consciousness correctly, one must first of all bring it back to its original source of inspiration, namely, the psychology of Aristotle and its development in medieval scholasticism, from which the concept of intentionality or "intentional in-existence" also derives. Yet it is precisely the Aristotelian roots of Brentano's thought - far from our "modern" way of thinking - that are responsible for the misunderstandings to which many of his theses have been subjected, in part already by his own students and Enkelschüler, and even more by many of today's "neo-Brentanians".

This is clear first and foremost in the use criticized above of the concepts of representation and self-representation in order to capture precisely the Brentanian concepts of intentionality and inner consciousness. Especially misleading is the application of the concept of representation to inner consciousness, such that it is conceived as self-representation, and even defined as the "core condition" (Kriegel, 2009, p. 107) of any proper theory of consciousness. This leads unavoidably to the modelling of self-consciousness on standard cases of representation, which are forms of hetero-representation, that is, representation by the mind of something other than itself. As Zahavi correctly observes:

Although Kriegel admits that self-awareness has special features that distinguish it from other mental phenomena, he nevertheless speaks of it in terms of an intentional self-representation (Kriegel, 2003c, p. 497). But one thought that comes to mind is whether "self-representation" is the right term, or whether it would not have been better to speak of self-presentation, selfpresence, or self-manifestation. Our acquaintance with our own experiences 
seems to have a presentational immediacy that is not easily captured by the term "representation". In fact, in most cases my experiences are present to me, rather than represented to me. There is no representational mediation. (Zahavi, 2004, pp. 73-74)

The representational interpretation of Brentano's point of view - maintained also by Zahavi himself, as well as the members of the Heidelberg School mentioned above - is largely due to a widespread misunderstanding of Brentano's theory of intentionality and of the concept of object that he uses in formulating it. In fact, Brentano uses the classical concept of object that was introduced by scholastic philosophy in order to address the problem posed by Aristotle in De anima of how reality is made accessible to the soul through our cognitive faculties. In the Aristotelianscholastic tradition, the object (obiectum, $\dot{\alpha} \nu \tau 1 \kappa \varepsilon i ́ \mu \varepsilon \nu o \nu)$ is always by definition the object of a faculty or a mental function, or of an epistemic or intentional attitude. The object is not a thing or an entity; rather, it refers to a thing or an entity according to the aspect or viewpoint in which it is mentally present. The same thing can therefore become multiple objects, since depending on the point of view from which one considers it, the same thing can become the object of many different intentional acts. In our cognitive activities, we always have something (a thing, an entity) as an object (Objekt): as visible, audible, thinkable, and so on.

In the scholastic conception, then, the object is first of all a formal object, because the cognitive functions or faculties of the soul are always oriented to forms. The formal object is precisely the aspect according to which the material object - the thing - becomes cognitively accessible. However, the formal object does not always correspond to a material object. In fact, it is possible to think of bizarre things like unicorns, which do not exist as material objects, or of something general or abstract, to which many individual things really correspond. In all these cases, we think of formal objects for which there is no corresponding thing in reality. However, we always think of them as extra-mental objects, independent of the mind. However, what really exists (if it does exist) is the thing, which like the mental act has a "sub-

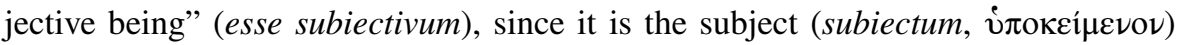
of many possible accidents or predicates. Thus, it is clear that in the modern era the concept of object has been transformed, and the object has become something external to the mind, which is represented by an idea that is present in the mind. ${ }^{6}$

The medieval concept of object thus conceptualizes the particular epistemic relationship that joins the mental act with the thing, the specific way in which things are presented to the soul without becoming real parts of it. Aristotle in De anima

\footnotetext{
${ }^{6}$ See Brentano, 1966, p. 341 (Von den Objekten, 30. März 1908, my translation): "The term 'object' is employed today in very different senses. Someone uses 'object' with the meaning of 'thing', and 'objective' with that of 'something really existing'. Some people consider the contraposition 'objective' vs. 'subjective' equivalent to that of 'psychical' vs. 'physical'. [...] However, in all these cases the linguistic usage has clearly degenerated; 'object' is an expression which is related to our mental activity, to thought in the most general sense of the word. Every thought is directed in some way to something as an object, perhaps also at the same time to more objects and in a different way. [...] When someone thinks, she is the thinking subject and has something as an object, perhaps also more than one thing."
} 
had described this presence as the presence in the perceptual act of the thing's form without its matter. As a cognitive and non-physical modification of the subject, sensation can be defined as an alteratio perfectiva, that is, the completion or realization of a disposition present in the subject. ${ }^{7}$ This is why sensation occurs not in the material or physical presence of the sensed things in the sensing subject, but in their objective presence: to feel the cold is not to be or to become physically cold, but to perceptively acquire something which is in our senses "as an object" (objective):

[W]e do not use the expression "objective" in the sense customary in recent times, but in the sense usually connected with the word by medieval Aristotelians (the scholastic term obiective). It allows a brief and precise characterization of the Aristotelian doctrine. Materially, as a physical quality, coldness is in the cold thing. As object, i.e., as something that is sensed, it is in him who feels the cold. ${ }^{8}$

In Aristotle, the coming into being of the perceptive act is explained in terms of the metaphysical theory of act and potency. Forms exist outside ( $\varepsilon \xi \omega \theta \varepsilon v)$ the soul (Aristotle, De an., II.5, 417b28) in a concrete union with matter, in the concrete unity and actuality of the synolon. The same form that inheres in the external sensible thing assumes a new actuality in virtue of an objective reception in the sensing subject (see Brentano, 1867, p. 81, Eng. p. 55). There is a precise correspondence between the actualization of the sensible (e.g., the actual sound) and the actualization of the sensitive faculty (the actual hearing). These two processes take place simultaneously and are only conceptually distinguishable (Aristotle, De an. III.2, 425b25-426a1), but this does not mean that the reality of the sensible coincides with that of perception. The sensible is sensible even when it is not being perceived; its "first actuality" is entirely independent of sensation, that is, its potential "second actuality" (Aristotle, De an., III.2, 426a15-26; cf. Cat. 7, 7b35, Metaph., IV.15, 1021a29). However, under no circumstances does this "second actuality" involve a duplication of the perceived object, as if that object had, in addition to its first-order actuality which is independent of perception, a second actuality as perceived in the act of perception (Aristotle, De an., II.5, 417a10-14; cf. Brentano, 1924-1928, I, pp. 184-185, Eng. pp. 100-101). The second actuality of the sensible form is identical to that of the sensitive act. A similar model applies to the intellectual process, in which the phantasms perform a function analogous to that of the sensibles. This Aristotelian idea underlies the medieval use of the term "object": the object becomes both the form (the aspect) of reality that becomes accessible to the subject through his cognitive operations and the way in which reality modally qualifies a perceptual or intellectual act addressed to it, with the result that this mental act is directed to its specific object.

\footnotetext{
7 Aristotle, De an., II.5, 417b2; cf. ibid., 417a16; Metaph., IX.6, 1048b28-33, and Brentano, 1867, p. 80, n. 4, Eng. pp. 54, 210.

8 Brentano, 1867, p. 80, n. 6, Eng. p. 210. Brentano refers here to "De an., III 2, 425b25, where Aristotle


very passage he cites in the letter to Anton Marty dated March 17, 1905 (in Brentano, 1930, pp. 86-89; Engl. pp. 77-79), where he defends his original conception of intentionality against absurd and erroneous interpretations, proposed even by some of his students. On this, see Sauer, 2006; Antonelli, 2001, 2015.
} 
In this way, it becomes clear what Brentano means by the "objective reception" (objektive Aufnahme) or "intentional in-existence" (intentionale Inexistenz) of the object. Such expressions are not to be interpreted as the existence of an object or its duplicate in the subject. They do not imply the existence of a particular type of entity that can be incorporated into the subject or that has a particular mode of existence which the object takes on in the mind. They consist simply of the actualization

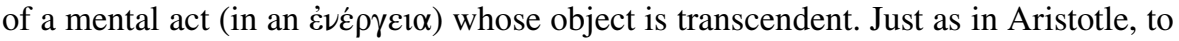
say that the form of the coloured thing is present in the matter means that something (a substance) is coloured, and that the form is present in the perceiver without the matter is to say that the perceiver actually perceives a colour (i.e., is a Farbsehender, a "colour seer"); thus, for Brentano, to say that colour has intentional inexistence is to say that someone actually perceives a colour, without in any way implying the presence in the perceiver of an immanent entity.

\section{Inner Consciousness}

This same Aristotelian model explains why actual perception, or, in Brentano's terminology, the act of seeing (for example), may be perception not only of the colour, but also of the seeing itself. ${ }^{9}$ The awareness of seeing is intrinsic to seeing merely because "the activity of the object of perception and of the sense is one and the same" (Aristotle, De an., III.2, 425b26; trans. Ackrill). It is for precisely this reason that Aristotle can state, in the chapter of De anima devoted to perceptual awareness (III.2), that "even that which sees is in a way coloured" (Aristotle, De an., III.2, 425b23) - a passage to which Brentano makes explicit reference on several occasions (see, e.g., Brentano, 1982, p. 26, Eng. pp. 28-29). The same form (e.g., colour) inhering in the actual sensible actualizes, through its objective reception, the sense itself, leading to the act of seeing (colour-seeing). The power or potency of seeing is thus realized through actual colour vision, which is the same thing as objective assimilation of colour. This actual colour vision simultaneously grasps itself - such that, on the one hand, the objectivized form (seen colour) refers to soul-independent material object colour, or a coloured thing, and, on the other hand, actual colour vision grasps itself as the current activity and reality of the soul. Seen-colour and colour-vision are, in fact, one and the same and only differ from the point of view

\footnotetext{
${ }^{9}$ In his Habilitationsschift on The Psychology of Aristotle (Brentano, 1867), Brentano, following Thomas Aquinas, attributed the awareness accompanying every act of sensation to an alleged "inner sense". He calls this "other sense" — unlike what can be legitimately ascertained according to Aristotle — "a special sense directed toward the inner movements of the sensitive part itself" (Brentano, 1867, p. 95, Eng. pp. 63-64), i.e., toward "sensations" and not toward qualities of the sensible object. However, this position opens up the possibility that the activities of this inner sense are unconscious or constitute an infinite regression at the level of mental activities. Through further philological and theoretical elaboration of the Aristotelian passages on self-awareness - conducted with Hermann Schell (1873), his pupil in Wurzburg and later a leading exponent of Catholic modernism in Germany - Brentano overcame the assumption that the numerical diversification of mental acts is a function of their objects. He later adopted the position that the number of presentations is a function of the number of mental acts, which as unitary wholes can include multiple parts within them.
} 
of perspective or relational character. "Therefore, the object of inner and outer consciousness is the same as reality, namely an energy (Energie) of the soul, which on the one side is a symbol of another reality, on the other side, is an activity and reaction (Tätigkeit und Wirkung) of the soul" (Schell, 1873, p. 168). Moreover, this "oneness and sameness" of the form (or object) allows one to appropriately assess the much-debated Regress and Duplication Problems, which, according to some scholars, Brentano's conception of inner consciousness is not able to overcome. ${ }^{10}$

The Aristotelian background of Brentano's theory of intentionality and inner consciousness becomes even more evident as soon as one considers that according to Aristotle, sensing and thinking are nothing but the sensed or thought object. Though in a certain sense (i.e., potentially) the mind is all existing things, it is actually and factually only what it senses or thinks (Aristotle, De an., III.8, 431b20; cf. Brentano, 1867, pp. 140-142, Eng. pp. 91-93). But a mind without actuality cannot know itself, since there is no mental state that the mind could know if there were not an in-existing object in the mind itself:

A presentation of the sound without a presentation of the act of hearing would not be inconceivable, at least a priori, but a presentation of the act of hearing without a presentation of the sound would be an obvious contradiction. The act of hearing appears to be directed toward sound in the most proper sense of the term, and because of this it seems to apprehend itself incidentally and as something additional (nebenbei und als Zugabe). (Brentano, 1924-1928, I, p. 180, Eng. p. 98)

The mind therefore can know itself only if it knows something other than itself. It does not seem accidental that in reconstructing Aristotle's conception of inner awareness, Brentano states: "Here it is apparent that his [Aristotle's] conception agrees entirely with our own" (Brentano, 1924-1928, I, p. 185, Eng. p. 102).

However, the object of the outer presentation - in the previously clarified classical sense - is only formally (i.e., according to its form) identical to the act of presentation, such that the existence of the precept is not guaranteed and deception can never be excluded. It is precisely for this reason, according to Brentano, that intentionality or primary consciousness is a one-sided or quasi relation in which the intentional object does not need to exist (Brentano, 1924-1928, II, p. 134, Eng. 272). ${ }^{11}$ In the inner presentation, and more generally in inner consciousness, instead, there subsists not only a formal correspondence between act and object, but also a real one, which is grasped in its full unity and totality. In the inner consciousness,

\footnotetext{
10 The Regress Argument states that Brentano's conception of inner consciousness leads to an (almost internal) infinite regress; the Duplication Argument maintains that inner consciousness leads to a duplication of the object, which appears twice, first in the presentation directed at $x$, and second in the inner presentation of the primary presentation of $x$ (for a detailed analysis of these arguments, see Textor, 2017, pp. 90-114, 134-141).

11 Incidentally, this thesis regarding the quasi-relational character of the mental relationship obtains for only an intermediate stage of Brentano's development of the concept of intentionality. He sets aside this thesis in the very last reistic phase of his thought after introducing a distinction between direct (modo recto) and indirect (modo obliquo) modes of presentation. According to that later distinction, one who thinks of someone seeing something red is also thinking in obliquo of a red thing that is thus seen. For a non-self-representational reading of Brentano's inner perception according to this distinction, see Seron, 2000.
} 
the mental act "is present to itself as content" (ist sich selbst als Inhalt gegenwärtig) (Brentano, 1924-1928, I, p. 180, Eng. 98, modified), i.e., is grasped as a selfintimating self-presence (Selbstgegenwart, see Schell, 1873, pp. 163, 170), which, however, is not the focus of attention but offered only "in passing" or "by the way". In inner perception there is, to use an expression from Sartre, an "indistinction" between subject and object (Sartre, 1948, p. 63); here, being and appearing (or being presented) coincide, whereas in outer perception the object is always a partial object, that is, an aspect of the thing manifesting itself. Unlike primary consciousness, inner awareness or perception implies an actual, fully overlapping relationship between perceiving and perceived, and precisely for this reason, it is veridical and self-evident - thus entailing the existence of the actually occurring mental activity. On the other hand, as we shall see in more detail shortly, this veridical self-evidence is also counterbalanced by something more "inconvenient": inner perception is also inescapably accessory and always pre-reflective, as in Husserl and Sartre.

Thus, underlying the self-representational reading and many of the criticisms formulated by the Heidelberg School and Zahavi regarding Brentano's conception of inner consciousness and its alleged dual or objectual character lies a misunderstanding of the Brentanian concept of object. As explained above, Brentano mobilizes the medieval concept of object, which refers not only to an external formal feature of the thing that transcends the subject but also to how this formal reality qualifies a cognitive act directed at the same reality. Brentano's conception of the object, coming from Aristotelian scholarship, and his mental-act-based medieval conception of perception and cognition, which has been overlooked by most interpreters, suggest we should abandon the representationalist reading of his theories of intentionality and consciousness and focus instead on his distinction between a primary and secondary object in each mental act and its implications.

\section{A Phenomenological Account of Inner Perception}

One might claim that when Brentano argues, following Aristotle, that actual visual experience is "in a way coloured", he means that there is a sense in which our experience is really perceptible and thus has a qualitative character that is immediately accessible to consciousness. Indeed, for Brentano, as for Aristotle, there is only one proper object of consciousness: the intentional (outer or primary) object. Consciousness of this primary or objectual consciousness does not constitute or generate any further content, nor does it have, in a strict sense, another object. Rather, its object is the same intentional object of primary consciousness, though it is considered through the lens of subjective experience:

[W] must become clear about whether we want to determine the number and the variety of presentations according to the number and variety of objects, or according to the number of mental acts in which the objects are presented. On the first alternative it is clear that we must say that in the case under consideration we would have several presentations and that they are of different kinds; so much so that one of them constitutes the content of another, while hav- 
ing a physical phenomenon as its own content. If this were true, the physical phenomenon must, to a certain extent, belong to the content of both of these presentations, to that of one as its explicit object, to that of the other as, so to speak, its implicit object. It would seem, therefore, as Aristotle also noted, to turn out that the physical phenomenon must be presented twice. Yet this is not the case. Rather, inner experience seems to prove undeniably that the presentation of the sound is connected with the presentation of the presentation of the sound in such a peculiarly intimate way that its very existence constitutes an intrinsic prerequisite for the existence of this presentation. (Brentano, 19241928, I, pp. 177-178; Eng. 98)

Brentano therefore explicitly rejects the view that a physical phenomenon is (re) presented twice. Consciousness is not a superadded, self- or inward-directed intention, as self-representationalists claim, because this would inevitably lead to a duplication of the physical phenomenon. Consciousness is simply the mental act appearing to itself as a mental phenomenon: its being experienced, or given, in a way the physical phenomenon is not. The mental act is not phenomenally experienced like sounds and colours but in another, distinct way, with a specific phenomenology and not as an intentional object.

In this sense, the redness we experience in observing a mature tomato is by no means an "intrinsic" property of the subject or of consciousness but of the world that transcends the subject. In the perceptual act, the mind is in direct relation to its phenomenal object, the so-called physical phenomenon. Acceptance of the "scientific image of the world" (Sellars, 1962) certainly leads Brentano to affirm that physical phenomena are mere "signs" (Zeichen) of something else for which they provide only an approximate indication (Brentano, 1924-1928, I, p. 28; Eng. 14), but he guards against the idealistic thesis that physical phenomena are sense data that exist within consciousness as mental entities. On the contrary, he claims that we perceive colours, not seen-colours, and sounds, not heard-sounds (ibid., pp. 129-132; Eng. 70-72). These phenomena are physical, although they are not ordinary physical entities that can be described in the physicalist language of the natural sciences. Physical phenomena are symbolic entities that, at the level of common sense, have an essentially practical value, since they essentially serve to regulate our behaviour; at the level of scientific investigation, they are the starting point for the natural sciences to recognize a more profound physical reality that has a space-time structure similar to that of the physical world of direct or phenomenal experience (ibid., p. 139; Eng. 76).

There is therefore only one content, the intentional one, which is causally determined by objective elements of the environmental context. With respect to this content, which is transparent to outer experience, inner consciousness is opaque, so to speak. This opacity also entails awareness of the "vehicle" of consciousness itself. This vehicle and its intentional modes or attitudes are, in a sense, experientially present to inner consciousness, yet without creating another object or further content. By "attitudes", I mean differences in the intrinsic qualitative character of each experience and its various intentional reference modalities, or rather, the three fundamental classes of mental acts and their inner divisions - presenting and, within 
presenting, presenting in an intuitive or conceptual way; affirming or denying; loving or hating, and willing). The "what-it's-likeness" intrinsic to any experience must be traced back to these types of attitudes. Through the prism of these attitudes, the 'phenomenal content, which is extrinsic to consciousness itself, is experienced as it is grasped by the mind in a specific way. Thus, every conscious mental act has its own particular subjective character, a specific phenomenology or "what it is like", and each form of intentionality has a phenomenal side or counterpart.

\section{Pre-reflective Self-Awareness}

If for Brentano thinking is essentially activity, or mental agency, as it is for Aristotle, then the act of thinking is inevitably accompanied by inner consciousness, albeit an accessory or "out of the corner the eye" consciousness or awareness. The perception of this cognitive act occurs $\dot{\varepsilon} \nu \pi \alpha \rho \dot{\varepsilon} \rho \gamma \omega$, en passant, or, as Brentano says, nebenbei und als Zugabe. Such an accompanying consciousness is thus elusive and non-reflective: as soon as one attempts to make it explicit, one is immediately brought back to the consciousness of the object, and not to the consciousness as such. On the other hand, this accessory consciousness is intrinsic, self-evident, and immediate, since it does not require the intervention of further acts, causal relationships, representations, or inferences. Despite its intrinsic and immediate character, however, inner consciousness is always secondary, in the sense that we are not aware and cannot be aware of our mental acts in the same way that we are conscious of the transcendent objects. Self-awareness is therefore not to be understood idealistically as a primary, elementary, and simple consciousness of ourselves, spinning in an empty circle or "in neutral", prior to any other form of "knowing", and operating independently of sensation. Instead, it can be said that we are only indirectly and imperfectly aware of what happens to us through the changes induced in us by and through the operations we exert on the objects, when we intend them according to sensation, thought, emotion, and will. In other words, what we innerly perceive is our actual conscious state compared to the one immediately preceding it and how it stands out against an indistinct background of other possible actualizations (cf. Dewalque, 2020, p. 37).

The elusive and pre-reflective character of inner perception explains why it can never be transformed into "inner observation" (innere Beobachtung). For observation postulates a real separation between perceiver and perceived, which is excluded in principle from the inner structure of the mental act (Brentano, 1924-1928, I, pp. 40-48, Eng. pp. 22-26). In order to move from inner perception to inner observation, it would be necessary to transform the secondary object into a primary one, and thus to make it distinct and explicit, which is impossible: "The truth is that something which is only the secondary object of an act can undoubtedly be an object of consciousness in this act, but cannot be an object of observation in it. Observation requires that one turns his attention to an object as a primary object" (Brentano, 1924-1928, I, p. 181, Eng. p. 99). However, this does not rule out the possibility that mental phenomena can be observed; indeed, through memory it is possible to 
retrospectively observe a mental phenomenon recently experienced, though such observation is only "similar" (in ähnlicher Weise) to observation in the proper sense (ibid.). Furthermore, because memory grasps the past mental phenomenon as a primary object, inner observation, unlike inner perception, is in principle biased and fallible. Once again, Brentano gives priority to intentionality, which founds selfawareness, not vice versa.

Brentano thus maintains — though in somewhat different terms from Husserl that experiences are present or self-manifested before becoming possible objects of reflection and hence of an explicit form of intentionality. Brentano distinguishes between perceptual consciousness $\dot{\varepsilon} \nu \pi \alpha \rho \dot{\varepsilon} \rho \gamma \omega$ and explicit or intentional consciousness. While the latter involves a duality of act and object, the former qualifies as non-dual or non-dyadic precisely because it does not entail a distinction between the experiencing act and the experienced object, but rather their fusion in a single whole. The self-representational reading of Brentano's conception, however, remains at least partially dual or dyadic, opening itself to the criticisms which have been made against Brentano by some of the previously mentioned members of the Heidelberg School, and then by Zahavi.

Against the self-representational reading the following argument may further be advanced. In perceiving a sound, I am certainly aware of my hearing, but am I also aware of this peculiar awareness? According to Kriegel, the perception of a sound and the awareness of hearing it are, according to Brentano, identical; to put it in Fregean terms, they are two senses of one and the same reference, namely, a single mental state (Kriegel, 2018a, p. 7). Because they are identical, the hearing of a sound can be conscious insofar as it represents itself or has itself as a secondary object. But defining inner consciousness in terms of self-representation inevitably introduces into consciousness precisely that separation between act and object, or subject and object, which opens the possibility of an intensive regress (Williford, 2006), or a nesting doll model multiplying endlessly the self-representation relationship, whereby " $a$ self-represents $a$ ", or $[a \mathrm{R} a]$, becomes " $a$ self-represents $a$ self-representing $a$ ", or $a \mathrm{R}[a \mathrm{R} a]$, which in turn becomes $a \mathrm{R}[a \mathrm{R}[a \mathrm{R} a]]$, and so on. This regress can be avoided only if the self-representation (the secondary object) of hearing involves in itself not only the perception of the sound, but also the perception which is aware of the sound and of itself (and this secondary consciousness is unstructured and pre-reflective).

Brentano himself had advanced the possible objection that inner consciousness might be made up of "boxes, one inside the other" (ineinandergeschachteltes), but immediately rejected it as being "cumbersome and contrary to experience":

The results of our investigation show [...] that the consciousness of the presentation of the sound clearly occurs together with the consciousness of this consciousness, for the consciousness which accompanies the presentation of the sound is a consciousness not so much of this presentation as of the whole mental act in which the sound is presented, and in which the consciousness itself exists concomitantly. Apart from the fact that it presents the physical phenomenon of sound, the mental act of hearing becomes at the same time its own object and content, taken as a whole. (Brentano (1924-1928, I, p. 182, Eng. p. 100) 
As convincingly argued by Mark Textor (2006) ${ }^{12}$ and more recently by Andrea Marchesi (2019), against Kriegel and before him Keith Hossack's "Identity Thesis" (Hossack, 2002), ${ }^{13}$ Brentano explicitly denies that primary and secondary consciousness are identical. To support this view, as Brentano points out in opposition to Alexander Bain and John Stuart Mill, would inevitably lead to subjective idealism (Brentano, 1924-1928, I, pp. 172-173, Eng. pp. 94-95). However, primary and secondary consciousness are only conceptually distinguishable parts of a single and unitary mental phenomenon:

The perception of hearing is not identical with the feeling we have toward hearing. They are divisives of the same reality, but this does not make them really identical with it and thus with one another. [...] [A] divisive, which I distinguish as a part in a real thing, cannot be called identical with this thing and hence with the other divisives which can be distinguished in it. A divisive never stands in a relation of real identity with another which has been distinguished from it, for if it did it would not be another divisive but the same one. (Brentano, 1924-1928, I, pp. 228-229, Eng. pp. 124-125)

Inner consciousness, according to Brentano, therefore includes not just the mental act in its relation to the primary object, but the act in its entirety with all its internal parts. Later, in one of the Appendices to the 1911 edition of Psychology from an Empirical Standpoint, he will further clarify this point:

In a single mental activity $[\ldots]$ there is always a plurality of references and a plurality of objects. As I have already emphasized in my Psychology from an Empirical Standpoint, however, for the secondary object of mental activity one does not have to think of any particular one of these references, as for example the reference to the primary object. It is easy to see that this would lead to an infinite regress, for there would have to be a third reference which would have the secondary reference as object, a fourth which would have the additional third one as object, and so on. The secondary object is not a reference but a mental activity, or, more strictly speaking, the mentally active subject, in which the secondary reference is included along with the primary one. Although now no infinite regress of mental references $\dot{\varepsilon} \nu \pi \alpha \rho \dot{\varepsilon} \rho \gamma \omega$ can arise,

\footnotetext{
${ }^{12}$ In order to refute Textor's thesis and support his own "Fregean identity interpretation of Brentano's theory of consciousness", Kriegel makes an elaborate analysis of Brentano's mereology. The fact that Brentano describes primary and secondary consciousness as "distinctional parts" (i.e., only conceptually and not really separable parts) of a single mental act, leads Kriegel (2018a, 2018b, pp. 28-43) to maintain that they are identical. Brentano does indeed explicitly argue in the Psychology, that "temporally they [i.e., the primary and secondary objects] both occur at the same time, but in the nature of the case (der Natur der Sache nach), the sound is prior. A presentation of the sound without a presentation of the act of hearing would not be inconceivable, at least a priori, but a presentation of the act of hearing without a presentation of the sound would be an obvious contradiction" (Brentano, 1924-1928, I, p. 180, Eng. p. 98).

${ }^{13}$ According to Hossack, Brentano would claim that "any conscious state is identical to the knowledge of its own occurrence, and that this is in fact the criterion of whether a state is conscious" (Hossack, 2002, p. 174). Cf. Kriegel, 2003a, pp. 121, 125, and also Caston, 2002, pp. 769, 792.
} 
it does not follow that mental activity is to be conceived as something simple. Even when mental references have the same object, they can still be different if the modes of reference are different. This is what we find to be the case with mental references $\dot{\varepsilon} \nu \pi \alpha \rho \dot{\varepsilon} \rho \gamma \omega$. (Brentano, 1924-1928, II, pp. 138-139, Eng. p. 215)

Brentano explicitly denies that primary and secondary consciousness - more precisely, primary and secondary perception - are identical, or even homogeneous, when he describes the presentations that underlie them as being "of very different sorts" (Brentano, 1924-1928, I, pp. 170-171, Eng. p. 94). In fact, while the presentation underlying primary consciousness is direct and non-elusive, the presentation at the basis of secondary consciousness always occurs on the side (nebenbei), as an addition (als Zugabe), and accessorily ( $\dot{\varepsilon} \nu \pi \alpha \rho \varepsilon \dot{\varepsilon} \gamma \omega$ ), and as such can be confused (undeutlich) and unclear (unklar). Moreover, while the judgement based on the primary presentation, that is, outer perception, is in principle always deceptive, to the point that "strictly speaking, so-called external perception is not perception" (Brentano, 1924-1928, I, p. 129, Eng. p. 70), inner perception acknowledges its object with assertoric "immediate, infallible self-evidence", so that "it is really the only perception in the strict sense of the word" (Brentano, 1924-1928, I, p. 128, Eng. p. 70).

Now, two things of very different kinds cannot by their nature be identical, but they can certainly belong to one and the same real unity. As Brentano puts it, "the unity of consciousness does not mean that consciousness, as it is in reality, excludes every plurality of parts of any kind. On the contrary, [...] what inner perception reveals to us can be differentiated into a variety of activities, and inner perception is infallible" (Brentano, 1924-1928, I, p. 233, Eng. p. 227).

\section{Conclusion}

One could say that Brentanian inner consciousness is essentially a pre-reflective (Brandl, 2013) and unstructured feature of inner life, thus anticipating the conception of consciousness typical of the phenomenological tradition shared by Husserl, Merleau-Ponty, and Sartre. As Brentano argued, however, inner consciousness can also serve as the foundation for an act of explicit apperception (Apperzeption) or noticing (Bemerken) by which inner consciousness becomes explicit and reflective consciousness. ${ }^{14}$ If this were not the case, the act of reflection would not grasp the actual conscious phenomenon but instead create or constitute it.

Inner consciousness owes its Cartesian certainty to this sui generis character as a non-partial and non-aspectual mode of self-presenting. It is in this pervasive selfpresenting character that the foundation of its direct, authoritative, and self-justifying evidentness lies. Self-awareness does not create anything: it can only adopt the content of primary consciousness. This is because our inner consciousness is empty,

\footnotetext{
14 See Brentano, 1924-1928, II, p. 277, Eng. p. 216; 1982, pp. 31-65, 150-151, 154-155, Eng. pp. 34-66, 159-160, 164-165; 1924-1928, III, pp. 1-36; 1933, p. 154, Eng. p. 117.
} 
so to speak: it adds nothing to the primary content, nor does it alter or subjectively distort it, but merely preserves it. Inner consciousness can be said to "modify" the primary content only in the sense that it inverts the "polarity" of experience, presenting the content as it is perceived through the lens of subjectivity. ${ }^{15}$ This is one of the principles of Brentanian empiricism: in the final analysis, inner consciousness depends on the sensory given.

The essence of inner consciousness is thus parasitic, so to speak. That is, it lives off the activity of intentional consciousness and the objects to which intentional consciousness is directed; it is thus secondary and dependent. If inner consciousness had the same characteristics as outer consciousness and could grasp only one aspect of itself, it would not be evident. Indeed, it would not be able to grasp itself as a whole and get a self-intimating glimpse of itself.

Funding Open access funding provided by Università degli Studi di Milano - Bicocca within the CRUICARE Agreement.

Open Access This article is licensed under a Creative Commons Attribution 4.0 International License, which permits use, sharing, adaptation, distribution and reproduction in any medium or format, as long as you give appropriate credit to the original author(s) and the source, provide a link to the Creative Commons licence, and indicate if changes were made. The images or other third party material in this article are included in the article's Creative Commons licence, unless indicated otherwise in a credit line to the material. If material is not included in the article's Creative Commons licence and your intended use is not permitted by statutory regulation or exceeds the permitted use, you will need to obtain permission directly from the copyright holder. To view a copy of this licence, visit http://creativecommons.org/licen ses/by/4.0/.

\section{References}

Antonelli, M. (2001). Seiendes, Bewußtsein, Intentionalität im Frühwerk von Franz Brentano. Alber.

Antonelli, M. (2015). Franz Brentano's intentionality thesis. A new objection to the "nonsense that was dreamt up and attributed to him." Brentano Studien, 13, 23-53.

Aristotle (1968). De Anima: Books II and III with passages from Book I. Trans. with introduction and notes by D. W. Hamlyn. Oxford University Press.

Armstrong, D. M. (1968). A materialist theory of the mind. Routledge \& Kegan Paul.

Boccaccini, F. (2015). Brentano or Husserl? Intentionality, consciousness, and self-consciousness in contemporary phenomenology of mind. Archivio di Filosofia, 83(3), 189-202.

Brandl, J. (2013). What is pre-reflective self-consciousness? Brentano's theory of inner consciousness revisited. In D. Fisette \& G. Fréchette (Eds.), Themes from Brentano (pp. 44-41). Rodopi.

15 According to Brentano's early modification theory, an adjective is determining, since it adds a property which gives the object a more precise characterization. In the expression "a tall man", we can observe a determining use of the attribute; this is not the case in "a dead man", however, since a dead man is no longer a man. Brentano introduced this distinction in the second volume of his Psychology (Brentano, 1924-1928, II, p. 2, n., Eng. p. 170) and developed it in his Descriptive Psychology, where he uses it to explain the ontological status of the intentional correlate, but also to argue that the retentional past is not a real thing. After his reistic turn, Brentano discarded the (non-real) intentional correlate (the thought-of-object); it became a purely verbal correlate, a mere synsemantikon, while the modification of the object was no longer attributed to its properties, but rather to the modal or adverbial character of the mental act. 
Brentano, F. (1867). Die Psychologie des Aristoteles, insbesondere seine Lehre vom nous poiêtikos. Kirchheim. Reprint Wissenschaftliche Buchgesellschaft, 1960. Eng. The psychology of Aristotle: In particular his doctrine of the active intellect. Trans. by R. George. University of California Press, 1977.

Brentano, F. (1924-1928). Psychologie vom empirischen Standpunkt, ed. O. Kraus, 3 vols. Meiner. Eng. Psychology from an empirical standpoint, ed. L. L. McAlister. Routledge, 1973; 2nd ed. with a new introduction by P. Simons. Routledge, 1995.

Brentano, F. (1930). Wahrheit und Evidenz, ed. O. Kraus. Meiner. Eng. The true and the evident. Trans. by R. M. Chisholm. Routledge, 1966.

Brentano, F. (1933). Kategorienlehre, ed. A. Kastil. Meiner. 2nd revised ed., Meiner, 1968. Eng. The theory of categories. Trans. by R. M. Chisholm \& N. Guterman. Nijhoff, 1981.

Brentano, F. (1966). Die Abkehr vom Nichtrealen, ed. F. Mayer-Hillebrand. Francke.

Brentano, F. (1982). Deskriptive Psychologie, ed. R. M. Chisholm \& W. Baumgartner. Meiner. Eng. Descriptive psychology. Trans. by B. Müller. Routledge, 1995.

Carruthers, P. (1996). Language, thought, and consciousness. Cambridge University Press.

Caston, V. (2002). Aristotle on consciousness. Mind, 111(444), 751-815. https://doi.org/10.1093/mind/ 111.444 .751

Chalmers, D. (1996). The conscious mind: In search of a fundamental theory. Oxford University Press.

Cramer, K. (1974). "Erlebnis": Thesen zu Hegels Theorie des Selbstbewußtseins mit Rücksicht auf die Aporien eines Grundbegriffs nachhegelscher Philosophie. In H.-G. Gadamer (Ed.), Stuttgarter Hegel-Tage 1970 (pp. 537-603). Bouvier.

Dewalque, A. (2020). The phenomenology of mentality. In D. Fisette, G. Fréchette \& H. Janoušek (Eds.), Franz Brentano's philosophy after one hundred years. From history of philosophy to reism (pp. 23-40). Springer.

Fichte, J. G. (1797). Versuch einer neuen Darstellung der Wissenschaftslehre. Philosophisches Journal, 7(1), pp. 1-20. Reprinted in Johann Gottlieb Fichtes sämmtliche Werke (Vol. 1, pp. 521-535). Veit und Comp., 1845.

Frank, M. (2015). Präreflexives Selbstbewusstsein: Vier Vorlesungen. Reclam.

Gennaro, R. J. (1996). Consciousness and self-consciousness. John Benjamin.

Henrich, D. (1970). Selbstbewußtsein: Kritische Einleitung in eine Theorie. In R. Bubner, K. Cramer \& R. Wiehl (Eds.), Hermeneutik und Dialektik (pp. 257-284). Mohr.

Hossack, K. (2002). Self-knowledge and consciousness. Proceedings of Aristotelian Society, 102(2), 163-181. https://doi.org/10.1111/j.0066-7372.2003.00048.x

Kapitan, T. (1999). The ubiquity of self-awareness. Grazer Philosophische Studien, 57(1), 17-43. https:// doi.org/10.5840/gps 1999573

Kapitan, T. (2006). Indexicality and self-awareness. In U. Kriegel \& K. Williford (Eds.), Self-representational approaches to consciousness (pp. 379-408). MIT Press.

Kriegel, U. (2003a). Consciousness as intransitive self-consciousness: Two views and an argument. Canadian Journal of Philosophy, 33(1), 103-132. https://doi.org/10.1080/00455091.2003.10716537

Kriegel, U. (2003b). Is intentionality dependent upon consciousness? Philosophical Studies, 116(3), 271307. https://doi.org/10.1023/B:PHIL.0000

Kriegel, U. (2003c). Consciousness, higher-order content, and the individuation of vehicles. Synthese, 134(3), 477-504. https://doi.org/10.1023/A:1022913321854

Kriegel, U. (2006). The same-order monitoring theory of consciousness. In U. Kriegel \& K. Williford (Eds.), Self-representational approaches to consciousness (pp. 143-170). MIT Press.

Kriegel, U. (2009). Subjective consciousness: A self-representational theory. Oxford University Press.

Kriegel, U. (2013). Brentano's most striking thesis: No representation without self-representation. In D. Fisette \& G. Fréchette (Eds.), Themes from Brentano (pp. 22-40). Rodopi.

Kriegel, U. (2018a). Brentano's dual-framing theory of consciousness. Philosophy and Phenomenological Research, 97(1), 79-98. https://doi.org/10.1111/phpr.12327

Kriegel, U. (2018b). Brentano's philosophical system: Mind, being, value. Oxford University Press.

Laerke, M., Smith, J. E. H., \& Schlisser, E. (Eds.). (2013). Philosophy and its history: Aims and methods in the study of early modern philosophy. Oxford University Press.

Lycan, W. G. (1987). Consciousness. MIT Press.

Lycan, W. G. (1997). Consciousness as internal monitoring. In N. Block, O. Flanagan \& G. Güzeldere (Eds.), The nature of consciousness: Philosophical debates (pp. 755-772). MIT Press.

Marchesi, A. (2019). Brentanian inner consciousness and the infinite regress problem. Dialectica, 73(12), 129-147. https://doi.org/10.1111/1746-8361.12261 
Montague, M. (2019). Intentionality: From Brentano to representationalism. In A. Kind (Ed.), Philosophy of mind in the twentieth and twenty-first centuries (pp. 200-232). Routledge.

Pothast, U. (1971). Über einige Fragen der Selbstbeziehung. Klostermann.

Rosenthal, D. M. (1986). Two concepts of consciousness. Philosophical Studies, 49(3), 329-359. https:// doi.org/10.1007/BF00355521

Rosenthal, D. M. (1993). Thinking that one thinks. In M. Davies \& G. W. Humphreys (Eds.), Consciousness: Psychological and philosophical essays (pp. 197-223). Blackwell

Sartre, J.-P. (1948). Conscience de soi et connaissance de soi. Bulletin de la Société Française de Philosophie, 42, 49-91.

Sauer, W. (2006). Die Einheit der Intentionalitätskonzeption bei Brentano. Grazer Philosophische Studien, 73(1), 1-26. https://doi.org/10.1163/18756735-073001001

Schell, H. (1873). Die Einheit des Seelenlebens aus den Principien der Aristotelischen Philosophie entwickelt. Scheuble.

Sellars, W. S. (1962). Philosophy and the scientific image of man. In R. Colodny (Ed.), Frontiers of science and philosophy (pp. 35-78). University of Pittsburgh Press. Reprinted in W. Sellars, Empiricism and the philosophy of mind (pp. 1-40). Routledge \& Kegan Paul, 1963.

Seron, D. (2020). Consciousness and representation. In D. Fisette, G. Fréchette \& H. Janoušek (Eds.), Franz Brentano's philosophy after one hundred years. From history of philosophy to reism (pp. 41-54). Springer.

Siewert, C. (2020). Consciousness and intentionality. In E. Zalta (Ed.), Stanford Encyclopedia of Philosophy, https://plato.stanford.edu/archives/spr2017/entries/consciousness-intentionality. Accessed December 18, 2020.

Textor, M. (2006). Brentano (and some neo-Brentanians) on inner consciousness. Dialectica, 60(4), 411432. https://doi.org/10.1111/j.1746-8361.2006.01080.x

Textor, M. (2013) Unity without self: Brentano on the unity of consciousness. In D. Fisette \& G. Fréchette (Eds.), Themes from Brentano (pp. 44-67). Rodopi.

Textor, M. (2017). Brentano's mind. Oxford University Press.

Thomasson, A. L. (2000). After Brentano: A one-level theory of consciousness. European Journal of Philosophy, 8(2), 190-210. https://doi.org/10.1111/1468-0378.00108

Williford, K. (2006). The self-representational structure of consciousness. In U. Kriegel \& K. Williford (Eds.), Self-representational approaches to consciousness (pp. 111-142). MIT Press.

Zahavi, D. (1998). Brentano and Husserl on self-awareness. Études Phénoménologiques, 14(27-28), 127-168. https://doi.org/10.5840/etudphen19981427/285.

Zahavi, D. (1999). Self-awareness and alterity: A phenomenological investigation. Northwestern University Press.

Zahavi, D. (2004). Back to Brentano? Journal of Consciousness Studies, 11(10-11), 66-87.

Zahavi, D. (2006). Two takes on a one-level account of consciousness. Psyche, 12(2), 1-9.

Publisher's Note Springer Nature remains neutral with regard to jurisdictional claims in published maps and institutional affiliations. 